Revue d'histoire de l'Amérique française

REYUE D.HISTOIRE DE L'AMÉRIQUE FRANÇAISE

\title{
Entre exportation et importation
}

\section{La création de la chanson québécoise selon la presse artistique,} 1960 - 1980

\section{Caroline Durand}

Volume 60, numéro 3, hiver 2007

URI : https://id.erudit.org/iderudit/015961ar

DOI : https://doi.org/10.7202/015961ar

Aller au sommaire du numéro

\section{Éditeur(s)}

Institut d'histoire de l'Amérique française

ISSN

0035-2357 (imprimé)

1492-1383 (numérique)

Découvrir la revue

Citer cet article

Durand, C. (2007). Entre exportation et importation : la création de la chanson québécoise selon la presse artistique, 1960 - 1980. Revue d'histoire de l'Amérique française, 60(3), 295-324. https://doi.org/10.7202/015961ar

\section{Résumé de l'article}

Cet article cherche à comprendre comment la chanson québécoise a gagné le statut d'emblème culturel national durant les années 1960 et 1970 et comment cette construction sociale a contribué à la redéfinition de l'identité collective survenue à cette époque. Il s'attarde sur l'appréciation des influences culturelles extérieures et des relations avec d'autres collectivités nationales, à travers l'étude de différents styles musicaux et de tentatives de carrières à l'étranger. Le rôle du discours de la presse artistique est analysé pour découvrir comment s'effectue la sélection entre la chanson québécoise qualifiée d'authentique et la musique populaire à valeur commerciale. Nous constatons que la presse artistique a participé à la construction identitaire de la collectivité en lui proposant une image d'elle-même et de sa culture qui correspond à sa réalité et à certaines de ses aspirations.
Tous droits réservés @ Institut d'histoire de l'Amérique française, 2007
Ce document est protégé par la loi sur le droit d'auteur. L'utilisation des services d'Érudit (y compris la reproduction) est assujettie à sa politique d'utilisation que vous pouvez consulter en ligne.

https://apropos.erudit.org/fr/usagers/politique-dutilisation/ 


\begin{tabular}{l} 
Entre exportation et importation. \\
La création de la chanson québécoise selon \\
la presse artistique, I960-I980 \\
\hline
\end{tabular}

\author{
Caroline Durand \\ Département d'histoire \\ Université McGill
}

\begin{abstract}
RÉSUMÉ • Cet article cherche à comprendre comment la chanson québécoise a gagné le statut d'emblème culturel national durant les années 1960 et 1970 et comment cette construction sociale a contribué à la redéfinition de l'identité collective survenue à cette époque. II s'attarde sur l'appréciation des influences culturelles extérieures et des relations avec d'autres collectivités nationales, à travers l'étude de différents styles musicaux et de tentatives de carrières à l'étranger. Le rôle du discours de la presse artistique est analysé pour découvrir comment s'effectue la sélection entre la chanson québécoise qualifiée d'authentique et la musique populaire à valeur commerciale. Nous constatons que la presse artistique a participé à la construction identitaire de la collectivité en lui proposant une image d'ellemême et de sa culture qui correspond à sa réalité et à certaines de ses aspirations.
\end{abstract}

ABSTRACT - This article seeks to understand how Québécois popular music became a national cultural symbol during the 1960s and 1970s and how this social construction contributed to redefining collective identity at the time. It sheds light on the role of external cultural influences and on relations with other national communities by studying various musical styles and attempts to develop careers abroad. The article analyses the discourse of the cultural press in order to show how so-called authentic Québécois songs were distinguished from popular music of merely commercial value. The cultural press played an important role in the construction of the collectivity's identity by providing it with an image

1. Je remercie Michèle Dagenais pour ses précieux conseils, les membres du comité de rédaction de la RHAF et les évaluateurs externes pour leurs commentaires utiles ainsi que le CRSH pour le financement accordé à cette recherche. 
of itself and of its culture that corresponded both to its reality and to some of its aspirations.

T orsqu'on tente de décrire la culture québécoise contemporaine et Lqu'on en cherche des caractéristiques, la chanson est fréquemment citée comme étant son expression par excellence. Une publication récente du gouvernement québécois l’introduit en ces termes: «La chanson populaire est certainement la discipline artistique qui a le plus contribué à faire connaître et apprécier la culture québécoise ici comme à l'étranger ${ }^{2}$.» Tous les artistes ne jouissent pas de ce statut d'ambassadeur de la culture nationale: si les chansonniers et leurs héritiers sont invariablement cités parmi les héros du panthéon de la chanson québécoise, plusieurs artistes demeurent considérés comme de simples vedettes commerciales ${ }^{3}$. Ainsi, des chansons comme Mon pays de Gilles Vigneault ou La Manic de Georges Dor sont perçues comme de véritables hymnes ${ }^{4}$, alors que d'autres, comme Je chante à cheval de Willie Lamothe ou Je ne suis qu'une chanson interprétée par Ginette Reno, ont moins de chances de figurer dans les anthologies de la chanson québécoise, même si elles ont connu un succès considérable.

La chanson québécoise prend son essor durant les années 1960 et 1970 et gagne son statut d'emblème culturel en même temps que s'effectue la sélection d'un groupe d'artistes et d'un corpus d'œuvres jugés authentiques. De fait, la chanson québécoise considérée emblématique n’englobe pas toute la production musicale populaire; elle se limite à un répertoire qui exprime "quelque vérité profonde sur le Québec, son peuple et son histoire ${ }^{5} »$. Selon Line Grenier, son authenticité reposerait sur plusieurs caractéristiques qui en feraient un moteur, un produit et un miroir de la

2. Isabelle Pauzé, Portraits du Québec (Sainte-Foy, Les Publications du Québec, 2003), 40.

3. Héros et vedettes se ressemblent parce qu'il s'agit de deux phénomènes communicationnels: leurs faits et gestes doivent être retransmis pour être connus du public. Comme l'affirme Frédéric Demers, le héros se distingue de la vedette par sa fonction identitaire et son rôle dans la consolidation des appartenances. C'est une figure rassembleuse qui illustre des aspirations partagées par une large part de la société. Frédéric Demers, Céline Dion et l'identité québécoise (Montréal, VLB éditeur, 1999), 30-32; 34-44; 56; 66-68.

4. Nous utilisons le mot tel qu'il est défini par le dictionnaire usuel Le petit Petit Robert: «un chant célébrant la gloire ou exprimant la joie et l'enthousiasme par rapport à une personne, une région, une patrie ou un peuple».

5. Line Grenier, «Si le "québécois pure laine” m’était chanté! Réflexions sur la spécificité de la musique francophone au Québec», dans Denis Saint-Jacques et Roger de la Garde, dir., Les pratiques culturelles de grande consommation, le marché francophone (Québec, Nuit blanche, CÉFAN, 1992), 95. 
québécitude: usage de la langue française, appropriation de la langue orale populaire, présence d'un discours politique pouvant être associé au nationalisme et musique combinant des sonorités nord-américaines et françaises $^{6}$. Line Grenier explique que la valorisation de certaines formes et caractéristiques artistiques résulte d'une construction sociale, un processus dynamique formé de l'ensemble des discours énoncés sur la chanson, qui permet à la collectivité de se reconnaître dans un produit culturel qu'elle perçoit comme spécifique ${ }^{7}$. Dans cet article, nous nous proposons d'explorer le rôle du discours médiatique dans la construction sociale de ce qui est considéré comme la chanson québécoise authentique en abordant un aspect rarement exploité dans les travaux sur la chanson: les relations entre le Québec et d'autres communautés nationales.

Une part importante de l'identité collective d'une société ou d'une nation se définit à travers les relations que le groupe entretient avec d'autres collectivités ${ }^{8}$. Ces relations peuvent toucher toutes les sphères d'activité du groupe, y compris les activités culturelles et artistiques ${ }^{9}$. Ainsi, les membres d'une collectivité comparent fréquemment leur culture à celle des autres afin de s'en distinguer ou de s'en rapprocher, selon les activités culturelles et selon l'époque. Plusieurs travaux, notamment de Yvan Lamonde, Gérard Bouchard et Jocelyn Létourneau ${ }^{10}$, ont analysé les diverses transformations qu'a connues l'identité québécoise en s'attachant à étudier son américanité, son ambivalence et les relations

6. Ibid., et Line Grenier, «Je me souviens... en chansons: articulations de la citoyenneté culturelle et identitaire dans le champ musical populaire au Québec», Sociologie et Sociétés, XXIX, $2(1997): 45$.

7. Sur la construction sociale de la chanson, voir les deux textes de Line Grenier précédemment cités et Line Grenier et V. Morisson, «Le terrain socio-musical populaire au Québec: "et dire qu'on ne comprend pas toujours les paroles...”” Études littéraires, 27, 3, (1995): 75-98.

8. Edmond Marc Lipiansky, "Comment se forme l'identité des groupes», dans Jean-Claude Ruano-Borbalan, dir., L'identité. L'individu, le groupe, la société (Auxerre Cedex, Sciences humaines éditions, Presses universitaires de France, 1998), 143-150 et Charles Taylor, «Les sources de l'identité moderne», dans M. Elbaz, A. Fortin et G. Laforest, dir., Les frontières de l'identité. Modernité et postmodernisme au Québec (Sainte-Foy/Paris, Les Presses de l'Université Laval/L'Harmattan, 1996), 251.

9. Dominique Schnapper, «Existe-t-il une identité française?» dans Ruano-Borbalan, dir., L'identité..., loc. cit., 99-301.

10. Voir surtout Yvan Lamonde, Allégeances et dépendances. L'histoire d'une ambivalence identitaire (Québec, Éditions Nota Benebene, 2001), 262 p.; Gérard Bouchard, «Une nation, deux cultures. Continuités et ruptures dans la pensée québécoise traditionnelle (1840-1960)», dans Gérard Bouchard et Serge Courville, dir., La constitution d'une culture: le Québec et l'Amérique française (Sainte-Foy, Les Presses de l'Université Laval, 1993), 3-47; et Jocelyn Létourneau, Passer à l'avenir. Histoire, mémoire, identité dans le Québec d'aujourd'hui (Montréal, Boréal, 2000), 194 p. 
entre le Québec et les métropoles politiques, économiques, religieuses et culturelles que sont la Grande-Bretagne, les États-Unis, Rome et la France.

Dans le présent article, nous considérons ces questions en lien avec l'exportation de la chanson québécoise et l'adoption de certains styles musicaux provenant du monde anglo-saxon. Nous montrons comment, notamment par la chanson, la collectivité québécoise en est venue à redéfinir son identité dans le cadre nord-américain, tout en demeurant fidèle à ses racines européennes. Par leur manière de rapporter les faits et gestes des artistes locaux à l'étranger, les journalistes de la presse artistique jouent un rôle clé dans ce processus en présentant aux Québécois des figures héroïques qui partent à l'assaut d'une France prestigieuse tout en se distinguant de l'ancienne mère patrie. Parfois, ces journalistes parlent aussi de pionniers qui explorent les possibilités de carrières américaines. Leur appréciation des styles musicaux anglo-saxons permet également d'intégrer à la culture québécoise des influences nord-américaines, sans toutefois mener à une acceptation inconditionnelle de tous les produits culturels américains. Plusieurs chanteurs et chanteuses deviennent de nouveaux héros de la culture populaire et expriment des aspirations collectives telles que le désir de reconnaissance et de distinction ainsi que la volonté de s'émanciper tout en intégrant avec succès des influences extérieures.

Notre article présente donc une analyse du discours journalistique sur la chanson qui éclaire l'image que l'on y donne des Québécois et de leur identité collective par rapport à d'autres collectivités de référence durant les années 1960 et 1970, une époque charnière à la fois pour l'histoire de la chanson et celle du Québec contemporain. Après avoir dressé un bref portrait du contexte et de l'historiographie, nous présenterons les sources utilisées et nous traiterons de deux thématiques qui ont intéressé les journalistes de l'époque. D'abord, nous aborderons l'exportation de la culture québécoise en décrivant la perception que les chroniqueurs avaient des artistes d'ici qui tentent leur chance en France ou aux États-Unis. De même, nous examinerons l'accueil réservé aux influences externes sur la musique populaire d'ici en comparant l'appréciation et l'acceptation de certains styles musicaux en provenance du monde anglo-saxon. Ainsi, il sera possible d'émettre quelques hypothèses concernant la définition de l'identité québécoise par rapport à la France et aux États-Unis.

Nous croyons que le discours médiatique, tout en circonscrivant une chanson québécoise perçue comme étant authentique, participe à la redéfinition de l'identité collective des Québécois et des Québécoises. Ce 
discours n'est pas ici considéré comme un simple témoin ou un reflet de ce que les individus pensent chacun de leur côté: il est envisagé comme un acteur de la construction sociale de la chanson québécoise et comme un des participants au processus de redéfinition identitaire. Par les commentaires qu'ils véhiculent sur la chanson, les médias sélectionnent ce qui est authentiquement québécois et ce qui ne l'est pas, à la fois dans la chanson et dans l'identité collective.

\section{CONTEXTE ET HISTORIOGRAPHIE}

Pourquoi étudier la chanson durant les décennies 1960 et 1970? La première raison découle du sujet lui-même : ces vingt ans sont perçus comme l'âge d'or de la chanson populaire au Québec. Il est généralement admis que c'est au cours de cette période que la chanson québécoise a pris son véritable envol. En effet, son public croît considérablement, le nombre d'artistes qui choisissent cette voie pour s'exprimer augmente de manière exponentielle, l'industrie du disque et du spectacle est dans une période de croissance accélérée et les médias accordent de plus en plus d'espace à la chanson en la diffusant et en la commentant ${ }^{11}$.

La période, celle de la Révolution tranquille ${ }^{12}$, en est aussi une qui permet d'explorer certaines transformations socioculturelles majeures dans l'histoire du Québec. Plusieurs d'entre elles sont bien connues: émergence et montée du néo-nationalisme, nombreuses réformes institutionnelles, accroissement et radicalisation du syndicalisme ${ }^{13}$, présence accrue de mouvements de gauche, identité de plus en plus reliée au territoire, au gouvernement provincial et à la langue française (ce qui s'exprime par la transformation des Canadiens français en Québécois et par les conflits linguistiques qui mèneront à l'adoption de lois pour la protection du français $\left.{ }^{14}\right)$. Comme l'exprimait Stéphane Venne par la voix de Renée Claude, plusieurs ont l'impression que «C'est le début d'un temps

11. Roger Chamberland, «De la chanson à la musique populaire», dans Denise Lemieux, dir., Traité de la culture (Sainte-Foy, Les Presses de l'Université Laval et Institut québécois de recherche sur la culture, 2002), 697-718.

12. Au sens strict, ce vocable désigne les années 1960-1966, soit la période où les réformes politiques et institutionnelles furent les plus nombreuses au Québec. Toutefois, l'expression peut également désigner l'ensemble des décennies 1960 et 1970, car ces dernières se caractérisent par une grande continuité au niveau des orientations gouvernementales et sont marquées par le keynésianisme et le néo-nationalisme. Paul-André Linteau, René Durocher, Jean-Claude Robert et François Ricard, Histoire du Québec contemporain, tome II: Le Québec depuis 1930 (Montréal, Boréal, 1989), 421-422.

13. Jacques Rouillard, Histoire du syndicalisme québécois (Montréal, Boréal, 1989), 287-372.

14. Marc V. Levine, La reconquête de Montréal (Montréal, VLB Éditeur, 1997), 404 p. 
nouveau "! Cette effervescence sociale et politique s'accompagne d'un bouillonnement culturel. C'est l'époque d'Hubert Aquin, de Gaston Miron, de Réjean Ducharme et de Michel Tremblay: la littérature québécoise se consolide, alors que les débats font rage autour de l'utilisation du «joual» et que certains auteurs s'engagent en faveur de l'indépendance politique du Québec. La musique populaire participe à ce dynamisme et est aussi l'objet de discussions sur la langue et l'engagement politique des $\operatorname{artistes}^{15}$.

Dès les années 1960 et 1970, la chanson québécoise est considérée comme un phénomène digne d'intérêt pour les sciences humaines. D’emblée, une tendance interprétative s'installe dans les travaux ${ }^{16}$ et persistera longtemps. On divise la chanson québécoise en deux courants distincts, soit les chansonniers, issus de la société traditionnelle, et la chanson populaire ou de divertissement, produite et distribuée par les structures propres aux sociétés industrielles. Dans son mémoire de mâ̂trise en sociologie, Pierre Guimond conclut que la chanson des chansonniers exprime l'identité nationale et les aspirations réelles de la jeunesse étudiante des années 1960, alors que la chanson populaire serait un phénomène anational, un produit de consommation universel sans contenu pertinent, destiné surtout aux jeunes adolescents, où la place de la vedette préfabriquée et éphémère est centrale. Suzanne Henri-Dumont, une autre sociologue s'inspirant principalement des travaux de Guimond, affirme d'ailleurs que seule la chanson des chansonniers permet une analyse du texte pour lui-même. Ce jugement, très répandu dans les années 1960 et 1970, imprégnera longtemps les travaux sur la chanson, nombreux à conclure que l'essence de la véritable chanson québécoise se trouve dans les textes plus que dans la musique et à chercher cette essence dans un répertoire déterminé, composé surtout des œuvres de chansonniers tels Félix Leclerc, Gilles Vigneault, Claude Gauthier et autres auteurs-compositeurs-interprètes.

Les nombreux livres publiés sous la direction de Robert Giroux, professeur de lettres et de communications à l'Université de Sherbrooke, s'inscrivent en partie dans ces tendances. Par exemple, dans La chanson en

15. Caroline Durand, Chanson québécoise et redéfinition identitaire, 1960-1980, mémoire de maîtrise (histoire), Université de Montréal, 2004, en particulier les chapitres 2 et 3.

16. Pierre Guimond, La chanson comme phénomène socio-culturel: analyse de ses divers aspects, mémoire de maîtrise (sociologie), Université de Montréal, 1968 et Suzanne Dumont-Henry, Analyse de contenu idéologique de la chanson au Québec: 1900-1919, 1960-1966, mémoire de maîtrise (sociologie), Université de Montréal, 1972. 
question $(s)^{17}$ et La chanson prend ses airs ${ }^{18}$, il suggère que la chanson peut être analysée à la fois en tant que texte et en tant que production culturelle. Or, il appert que dans la plupart des textes parus dans ces recueils, les auteurs emploient l'analyse de contenu pour les chansonniers et celle de la structure de production pour les chanteurs populaires. Si cette perspective permet des analyses de contenu profondes, elle s'avère souvent limitative, car elle présuppose l'existence d'une "vraie» chanson québécoise et de catégories fixes à l'intérieur de celle-ci. Une autre idée fréquemment émise sur la chanson associe authenticité et engagement des artistes envers le nationalisme québécois. Jacques Aubé remet cette association en cause dans Chanson et politique au Québec ${ }^{19}$. Il quitte l'analyse textuelle pour se pencher sur la participation des artistes à des spectacles bénéfices pour des causes politiques dans les années 1960-1970, tous styles musicaux confondus. Son analyse permet de constater que plusieurs artistes associés à la "chansonnette" participaient à ces événements autant, et parfois même plus souvent, que certains chanteurs ayant des textes dits «engagés». Cela porte à croire que les associations entre chanson dite authentique, chansonniers et artistes engagés ne sont pas fixes et absolues.

Compte tenu des limites de la majorité des ouvrages portant sur la chanson québécoise, notre démarche s'est surtout inspirée des travaux adoptant une perspective ouverte aux approches post-structuralistes. Ainsi, dans ses écrits, Line Grenier ${ }^{20}$ interroge le caractère soi-disant spécifique de la chanson québécoise et étudie le processus de construction sociale de la musique populaire par l'analyse des discours émis à son sujet, sans se limiter à un corpus d'œuvres ou à un groupe d'artistes en particulier. Le livre de Frédéric Demers, Céline Dion et l'identité québécoise ${ }^{21}$, nous a aussi beaucoup inspirée. En décrivant comment cette chanteuse est héroïsée par la presse artistique, Demers ne se limite pas à étudier la chanson populaire pour son contenu, mais en tant que source de figures identitaires valorisées par les médias, auxquelles le public s’identifie.

17. Robert Giroux, dir., La chanson en question(s) (Montréal, Triptyque, 1985), 194 p.

18. Robert Giroux, dir., La chanson prend ses airs (Montréal, Triptyque, 1993), 232 p.

19. Jacques Aubé, Chanson et politique au Québec, 1960-1980 (Montréal, Triptyque, 1990), 134 p.

20. Line Grenier, «Si le «"Québécois pure laine”...», loc. cit., et Line Grenier, "Je me souviens"... en chansons", loc. cit.

21. Frédéric Demers, Céline Dion et l'identité..., op. cit. 


\section{LES SOURCES: LA PRESSE ARTISTIQUE}

Notre analyse du discours médiatique se fonde sur trois journaux: le journal «à potins» Échos-Vedettes, un hebdomadaire, et les pages artistiques de deux quotidiens montréalais, La Presse et Le Devoir. Ces trois publications sont désignées par l'expression journaux artistiques, même si les deux quotidiens sont des journaux d'information générale. Ce choix arbitraire s'explique par le fait que nous avons employé presque exclusivement les parties de ces quotidiens consacrées à la vie culturelle et artistique et ne vise qu'à alléger le texte. Nous nous sommes limitée à des journaux de langue française, car à l'époque, la communauté québécoise se définit comme un groupe strictement francophone. Comme notre objectif est de comprendre comment la collectivité nationale se perçoit elle-même, nous n'avons pas effectué de recherche du côté des journaux anglophones publiés au Québec. Soulignons aussi le caractère métropolitain de ces sources, ce qui peut influencer le regard posé par les journalistes sur certains phénomènes, comme nous le verrons dans le cas du western. Les journaux artistiques constituent une source privilégiée pour l'étude de l'histoire de la chanson au Québec. Ces publications font partie de toute une "machinerie médiatique créatrice de renommée et de visibilité22», comprenant également la radio et la télévision. Leur développement est un des indices de la croissance des industries culturelles. Dans son étude consacrée aux journaux artistiques, Mario Fontaine dénombrait en 1978 seize publications appartenant au genre des «journaux à potins ${ }^{23}$ ». Tirant au total à environ 700000 exemplaires par semaine, ils se consacrent presque exclusivement aux vedettes locales ${ }^{24}$. Dans les quotidiens et les hebdomadaires d'information générale, le monde artistique local prend une place de plus en plus importante. Les chroniques consacrées aux arts et spectacles, qui n'occupent que quelques colonnes au début des années 1960, deviennent progressivement des cahiers complets qui peuvent même prendre la forme d'un magazine distinct du journal lui-même, comme en témoigne l'existence de Spec, un cahier préparé par une équipe rédactionnelle indépendante et paraissant chaque jeudi dans La Presse de 1969 à 1972. Les journaux artistiques font partie des structures médiati-

22. William Straw, «L'industrie du disque au Québec», dans Denise Lemieux, dir., Le Traitéde la culture, loc. cit., 842 .

23. Mario Fontaine, Tout sur les p'tits journaux z'artistiques ou comment s'endormir avec le cour qui palpite (Montréal, Éditions Quinze, 1978), 14.

24. Ibid., p. 151. 
ques qui soutiennent les industries culturelles reliées à la chanson: ils critiquent les disques et les spectacles, ils en font la publicité, ils publient parfois des palmarès, ils traitent des différents événements qui se produisent dans le monde artistique et surtout, ils parlent de la vie professionnelle et personnelle des artistes et des vedettes de la chanson.

Échos-Vedettes constitue une publication très intéressante en raison de sa représentativité, de son tirage et de sa longévité. Fondé en 1963, c’est le plus connu des journaux «à potins», une catégorie incluant également des titres comme Photo-Journal, Nouvelles Illustrées et Nouvelles et Potins ${ }^{25}$. Un seul d'entre eux nous semble donc suffisant pour les représenter. Plusieurs de ces publications ont d'ailleurs été fondées ou achetées par le même propriétaire, Pierre Péladeau. Bien que la qualité de l'information contenue dans Échos-Vedettes soit parfois mise en doute par d'autres médias, elle a tout de même déjà eu, parmi les publications du même ordre, une réputation de franchise, de qualité et de véracité ${ }^{26}$. Durant l'époque étudiée, ce journal connaissait un succès considérable, tirant à 127000 exemplaires en 1971 et à 155000 par semaine en $1980^{27}$. C'est pourquoi chaque numéro d'Échos-Vedettes a été systématiquement dépouillé depuis sa fondation jusqu'à la fin de 1979.

Le choix du quotidien La Presse se justifie encore plus aisément. S’adressant à un large public, il est diffusé partout au Québec et imprimé à 179199 exemplaires en 1971 et à 165872 en $1979^{28}$. De plus, son contenu sur les arts et la culture est très riche. Dès le début des années 1960, l'édition du samedi offre des chroniques sur les arts et spectacles et à partir de 1961, un cahier distinct traite du cinéma, des beaux-arts, de la littérature, de la radio, de la télévision, du théâtre et de la musique. Tout au long des vingt années étudiées, la place accordée à la chanson varie. Durant les années 1960, ce sont surtout les chroniqueurs du cahier Arts et lettres qui couvrent ce domaine et souvent, les mêmes journalistes critiquent les concerts de musique classique et les disques des chanteurs et chanteuses populaires. En 1969, c'est dans le magazine Spec que les articles à ce sujet se retrouvent, alors que vers la fin des années 1970, la chanson est couverte

25. Ces journaux ont toutefois un contenu très semblable et Mario Fontaine affirme avec justesse: «ces organes présentent une marchandise uniforme sous des emballages différents, se distinguent par la forme à défaut de par le fond", Ibid., p. 21.

26. Ibid., p. 24.

27. Statistiques culturelles du Québec, 1971-1982 (Québec, Institut québécois de recherche sur la culture, 1985), tableau 4.16.

28. Ibid., tableau 4.6. 
dans le cahier Arts et spectacles. Remarquons également que d'autres cahiers, comme la section Magazine, paraissant dans les années 1960, traitent aussi à l'occasion de musique populaire.

Nous avons fait du journal Le Devoir un usage différent. Malgré un tirage plus modeste (40 157 exemplaires en 1971 et 42044 en 1979²9), Le Devoir jouit d'une grande influence dans les milieux intellectuels et politiques et possède une réputation de rigueur et de qualité qui en fait une source incontournable pour quiconque s'intéresse à la presse québécoise. Cependant, ce quotidien n'a pas fait l'objet d'un dépouillement systématique, comme pour les deux autres sources employées. Après une première analyse du contenu d'Échos-Vedettes et de La Presse, nous avons plutôt sélectionné des dates où se sont produits des événements qui ont suscité l'intérêt de ces deux journaux et nous avons consulté Le Devoir autour de celles-ci, afin de vérifier l'existence de variations dans le discours journalistique.

Étant donné la grande variété des parcours des journalistes ayant œuvré dans la presse artistique, il est difficile de dresser un portrait d'ensemble et d'identifier des caractéristiques qui pourraient influencer le discours médiatique sur la chanson. Certains journalistes cités sont toujours actifs aujourd'hui, comme René Homier-Roy et Claude Gingras. Edward Rémy, un des fondateurs d'Échos-Vedettes, a aussi eu une longue carrière. D'autres sont même devenus politiciens et souverainistes, comme Lise Payette et Pierre Bourgault. Même si ces derniers n'étaient pas des chroniqueurs artistiques, ils se sont intéressés à la chanson. D’autres encore sont demeurés dans le journalisme mais ont suivi des voies qui n'ont que peu à voir avec la politique ou la musique, comme Jacques Duval, devenu un chroniqueur automobile bien connu, et Pierre Trudel, qui couvre le domaine sportif à CKAC et dans La Presse. Plusieurs journalistes semblent, par ailleurs, avoir connu de courtes carrières. Enfin, quelques-uns sont restés anonymes, les auteurs de certains articles n'étant pas identifiés.

\section{S'ÉMANCIPER, CONQUÉRIR ET EXPLORER}

PAR L'EXPORTATION DE LA CHANSON

\section{En France}

Les exemples de chanteurs et chanteuses québécois qui ont tenté de conquérir le public français sont nombreux. Il est pratiquement impossible de passer à côté du cas de Félix Leclerc, dont les débuts parisiens en 1950 
sont perçus, dès le début des années 1960, comme un des événements fondateurs de la jeune histoire de ce qui est nommé alors la chanson canadienne ${ }^{30}$. Durant de nombreuses années, Félix Leclerc est considéré comme le seul artiste québécois qui soit parvenu à s'imposer réellement en France, même à la suite du passage de plusieurs autres sur les mêmes scènes que lui ${ }^{31}$.

Durant les années 1960, certains commentaires effectués au sujet de la carrière française de Leclerc expriment sa distinction au regard des artistes européens:

Les Européens ont appelé Félix Leclerc «le Canadien». Le qualificatif était fondé sur une réalité indiscutable. La grande majorité des chansons de Leclerc ne pourraient pas avoir été écrites par un Français ou un Belge. En raison de certaines formes de langage et de certains mots, certes, mais plus encore, et c'est ce qui semble essentiel, en raison d'un "esprit ${ }^{32}$.

L'auteur cherche ici à décrire Félix Leclerc comme un artiste différent des chansonniers français, même s'il chante dans un langage qualifié d'universel. Pour accentuer cette distinction, les journalistes de l'époque n'hésitent pas à le décrire en ces termes: «homme d'ici», "poète du Canada français», "paysan ${ }^{33}$ ", "habitant ${ }^{34}$ ». Ils évoquent aussi fréquemment les lieux géographiques québécois : par exemple, ils citent le pays, le territoire, la terre ou la nature en parlant des thèmes de ses chansons.

Toutefois, les journalistes projettent également l'image d'un Félix Leclerc comme membre à part entière de la chanson française. On affirme que: «En France on n'écrit plus, depuis 18 ans, d'histoire de la chanson sans faire une place importante à Félix Leclerc ${ }^{35}$ » et que «Il est identifié à la chanson française dont il représente une étape, une page d'histoire ${ }^{36}$.»

30. Jacques Keable, «La ligne de vie de la chanson canadienne », La Presse, cahier Arts et lettres, 9 décembre 1961, 3.

31. Pierre Saint-Germain, "Les Parisiens ont découvert en Leclerc un grand conteur», La Presse, $1^{\text {er }}$ avril 1967, 42, et Anonyme, «En France, Félix Leclerc demeure le plus grand des Québécois », Échos-Vedettes, 22 novembre 1975, 12.

32. Jacques Keable, "La ligne de vie de la chanson canadienne », La Presse, cahier Arts et lettres, 9 décembre $1961,3$.

33. C. G. [Claude Gingras], «Le nouveau Félix Leclerc», La Presse, 16 juin 1962, 22.

34. Jean O’Neil, «Félix Leclerc, le bonheur et le théâtre», La Presse, cahier Arts et lettres, 19 janvier $1963,2$.

35. [Joseph] Rudel-Tessier, "Oui, Félix Leclerc est un homme heureux», La Presse, cahier Arts et lettres, 20 février 1969, 3.

36. Edward Remy, «Félix s’exile!», Échos-Vedettes, 20 mai 1967, 4. 
On lui attribue même l'exploit d'avoir ouvert la porte à Georges Brassens, Léo Ferré et Jacques Brel ${ }^{37}$ ! C’est sans doute pour cette raison que celui qui est nommé «notre» Félix Leclerc est considéré comme étant «tout aussi chez lui en France qu'au Canada ${ }^{38}$ ». En somme, Félix Leclerc est perçu comme un pionnier de la chanson québécoise pour être le premier à avoir connu le succès en France grâce à son «esprit » typiquement canadien, mais il est aussi décrit comme un artiste intégré à l'ensemble de la chanson française.

Le cas de Gilles Vigneault est différent. Considéré lui aussi comme un des pionniers de la chanson québécoise, il se rend à plusieurs reprises en France pour y donner des récitals. Globalement, les journalistes accentuent beaucoup plus la différence entre Gilles Vigneault et les Français qu'ils ne le faisaient pour Félix Leclerc. Ainsi, lors de son premier voyage en France en 1963, Échos-Vedettes évoque la possibilité qu'il perde son accent québécois $^{39}$. Avant son passage à l'Olympia en 1966, on lui demande s'il craint que le public parisien ne comprenne pas toutes les paroles de ses chansons ${ }^{40}$. Cette distinction au niveau du langage et la possibilité que les Français ne le comprennent pas sont fréquemment évoquées dans le cas de Gilles Vigneault.

Cette différence est parfois décrite comme une attraction pour les Parisiens qui assistent aux spectacles de Vigneault. Interrogeant des membres du public, Pierre Saint-Germain les cite ainsi : «Ce que nous apercevons à travers ses ouvres, c'est une image du Canada français, ont-ils précisé, et l'accent est inséparable de cette image bien que nous ayons du mal à le saisir ${ }^{41}$.» L'exotisme du personnage ne provient pas uniquement de son accent: son lointain village d'origine, Natashquan ${ }^{42}$, est fréquemment évoqué, de même que les thématiques locales de chansons comme La danse à Saint-Dilon, Jack Monoloy, Mon pays...

37. Pierre Saint-Germain, «Félix à Paris: des roses à gogo au compositeur, quelques épines à l'auteur dramatique », La Presse, cahier Arts et lettres, 9 janvier 1965, 1.

38. Edward Remy, «Félix s'exile!», loc. cit., 4.

39. Anonyme, «L'accent français? Gilles Vigneault "s'en ai clairé de juste" là-bas à Paris ", Échos-Vedettes, 2 novembre 1963, 21.

40. Anonyme, "Vigneault à Paris : nerveux, oui, mais pas plus que ça!», La Presse, cahier Arts et lettres, 12 février 1966, 2.

41. Pierre Saint-Germain, «Vigneault: Paris d'accord; mais jamais pour deux ans » La Presse, cahier Arts et lettres, 20 novembre 1965, 7.

42. Anonyme, «L’accent français? ... », loc. cit., et Lucien Rioux, «La grande revue française Constellation fait l'éloge de Gilles Vigneault», Échos-Vedettes, $1^{\text {er }}$ juillet 1967, 4 (réimpression de l'article paru dans Constellation). 
Le chansonnier se dit bien décidé à ne pas changer pour le public de Paris $^{43}$ et les journalistes lui donnent raison en rapportant ses succès écla$\operatorname{tants}^{44}$. Les passages de Gilles Vigneault à Paris sont souvent qualifiés de triomphes et les termes employés sont parfois dithyrambiques: le 15 octobre 1966, Échos-Vedettes titre: "Vigneault et Pauline [Julien] bloquent la vague d'américanisme ${ }^{45}$ !» à la suite d'une de leurs prestations parisiennes. Cependant, la différence n'est pas toujours garante de succès: «Et le public ne sait pas voir, ne sait pas entendre, ne comprend pas. Les termes lui échappent. La violence poétique aussi. Il y a divorce entre l'artiste et l'auditoire ${ }^{46}$ ", dit-on au sujet de sa participation à une revue musicale présentée à l'Olympia en septembre 1967. Lors d'un autre spectacle, Le Devoir commente ainsi: «Les Français égarés à Bobino n’en saisissent pas un $\operatorname{mot}^{47}$.» Gilles Vigneault est décrit comme un chansonnier très différent des artistes auxquels sont habitués les Français. Son exotisme les attire et les déboussole tout à la fois.

Le premier passage de Robert Charlebois à l'Olympia en 1969 offre un autre bel exemple d'artiste québécois incompris par le public français. Alors qu'il est au sommet de sa gloire au Québec et qu'il commence à être connu en France avec Lindbergh, Robert Charlebois, accompagné de Louise Forestier et du Jazz Libre du Québec, traverse l'Atlantique pour faire la première partie du spectacle d'une chanteuse française qui a connu du succès dans les années 1930, Georgette Plana. Si les journaux d'ici citent quelques critiques positives publiées dans la presse française ${ }^{48}$, ils rapportent surtout la consternation du public:

43. Claude Gingras, "Vigneault décidé à rester le même à Montréal, Paris ou Saint-Fabien", La Presse, cahier Arts et lettres, 3 septembre 1966, 13.

44. Rémy le Poittevin et Sylviane Cahay, "Il était minuit passé, et le public parisien, enthousiasmé, exigeait encore d'autres rappels", Échos-Vedettes, 10 septembre 1966, 5-7; Pierre SaintGermain, «Malgré leur succès parisien, Vigneault et Julien pensent avec nostalgie au Canada... », La Presse, cahier Arts et lettres, 15 octobre 1966, 3; Lucien Rioux, "Gilles Vigneault, le Brassens canadien ", Le Devoir, 21 avril 1969, 8 (réimpression d'un article paru dans le Nouvel Observateur); et Catherine Benrubi, «Paris ovationne Vigneault», Échos-Vedettes, 26 avril 1969, 7-9.

45. Sylviane Cahay, «Devant le public le plus connaisseur de Paris... Vigneault et Pauline bloquent la vague d’américanisme!», Échos-Vedettes, 15 octobre 1966, 16-17.

46. Jean-Claude Deret, "“Vive le Québec!” À Paris», Échos-Vedettes, 30 septembre 1967, 19.

47. Jean-Guy Pilon, "Demi-succès pour Pauline Julien et Vigneault», Le Devoir, 19 octobre $1966,8$.

48. Anonyme, "Charlebois à Paris. Grincements de dents et enthousiasme », Le Devoir, 3 avril 1969, 14. 
On a carrément l'impression que la moitié de la salle, terrorisée, va sortir en poussant de grands cris. [...] Ce n'est pas que les Français n’ont pas aimé le spectacle que «la gang à Charlebois» donne à l'Olympia depuis mercredi de la semaine dernière. Pas vraiment, en tout cas. C'est pire : ils ne comprennent pas, ils n'ont jamais rien vu de pareil, ils n’ont probablement rien imaginé de tel non plus ${ }^{49}$.

Si le public de l'Olympia réserve aux chansons de Charlebois un accueil plus que tiède et que les journalistes se demandent s'il a compris quelque chose $^{50}$, la personnalité de l'artiste soulève aussi des questions dans la presse québécoise. Son attitude de rock star irrévérencieuse qui ne se soucie pas de l'opinion des autres fait en sorte que Pierre Trudel, du journal Échos-Vedettes, se demande si les Français ne vont pas bouder ce phénomène ${ }^{51}$. Dans le même numéro, on se plait d'ailleurs à raconter ses disputes avec le directeur de l'Olympia à propos de la sonorisation de son spectacle et à rapporter les propos qu'il tient lors de ses entrevues en essayant de rendre par écrit son langage typiquement québécois. ÉchosVedettes affirme qu'il sacre en ondes et que les Français ne comprennent certainement pas l'usage de mots religieux pour jurer ${ }^{52}$. Cet article insiste également sur l'usage d'anglicismes tels que «fun», "too much», «cool», «bag» et sur l'élision fréquente d'articles et de syllabes: «C't’une folle», «C'pas grave», «tu r’viens».

L'accueil mitigé de ce premier spectacle de Robert Charlebois en France et les fameux emportements scéniques qui ont précipité son départ de l'Olympia ne semblent pas diminuer la popularité de l'artiste au Québec. Dès le mois suivant, un critique affirme qu'il est un showman authentique, qu'il a une personnalité attachante, qu'il est une vedette incontestée et un phénomène indiscutablement brillant ${ }^{53}$. Il est possible que tout le bruit autour de cette expérience ait contribué à mousser sa popularité et à construire son image de rock star. Quoiqu'il en soit, son passage à Paris peut être considéré comme une manifestation supplémentaire du désir des Québécois de se distinguer culturellement de la France durant les

49. René Homier-Roy, "Charlebois a pas ri à Paris», La Presse, magazine Spec, 3 avril 1969, 6.

50. Ibid., 7 .

51. Pierre Trudel, «Échos-Vedettes accompagne Robert Charlebois à Paris!", Échos-Vedettes, 5 avril $1969,2$.

52. Ibid., 3-4.

53. Pierre Brousseau, "Charlebois casse tout à la Comédie-Canadienne», Échos-Vedettes, 24 mai $1969,7$. 
années 1960 et 1970: les Français ne peuvent tout simplement pas comprendre celui qui «souffre de toutes nos aliénations et toutes nos faiblesses collectives $^{54}$ ", affirment les critiques.

Pour sa part, Diane Dufresne est décrite comme la fidèle héritière de Robert Charlebois: une journaliste la surnomme même «la Charlebois en jupon ${ }^{55}$ ». Mais dans son cas, les articles parlent de triomphe: «Diane Dufresne a présenté aux Français quelque chose de différent et ils marchent à fond même s'ils n'y comprennent rien ${ }^{56}$ !» Encore une fois, le fait que la chanteuse s'adresse aux Français avec l'accent québécois semble particulièrement apprécié, de même que sa manière d'affirmer haut et fort que sa vraie carrière est au Québec et non à Paris, n’en déplaise au patron de l'Olympia et au public français ${ }^{57}$. D'abord, Le Devoir dit qu'elle déconcerte Paris ${ }^{58}$, mais finalement La Presse annonce: «Diane Dufresne les a eus, les Français ${ }^{59}$ ». Les journaux nous montrent donc Diane Dufresne comme une artiste qui est parvenue à conquérir le public français tout en gardant son accent et en manifestant clairement sa volonté de demeurer fidèle au Québec.

Malgré tout ce discours visant à distinguer artistes québécois et français, le passage des vedettes locales dans la capitale française demeure un événement important aux yeux de la presse artistique. Ces spectacles sont abondamment couverts par les journalistes et les journaux n’hésitent pas à envoyer à l'occasion un membre de la rédaction sur place. Le vocabulaire employé pour décrire ces spectacles exprime éloquemment leur caractère héroïque : on parle de lutte ou de bataille pour conquérir un public décrit comme difficile et récalcitrant et lorsque le succès est au rendez-vous, il est souvent qualifié de triomphal.

Or, cette importance est sans doute exagérée par la presse artistique. Les articles relatant ces spectacles en France nous apprennent que derrière

54. Raymond Laplante, «Un père tranquille au show Charlebois: “J’sais pu où chu rendu!" ”, La Presse, magazine Spec, 14 août 1969, 7.

55. Christiane Berthiaume, «Diane Dufresne: la Charlebois en jupon!», La Presse, 26 avril 1973, D1.

56. Pierre Trudel, "Diane Dufresne: le triomphe de l’originalité», Échos-Vedettes, 28 juillet $1973,4$.

57. Christiane Berthiaume, "Diane Dufresne, "l'achalante" ", La Presse, 20 septembre 1973, B1; et Gisèle Tremblay, «Diane Dufresne, L’Opéra-Cirque a trouvé son théâtre», Le Devoir, 25 septembre $1973,14$.

58. A.F.P (Agence France-Presse), «Diane Dufresne déconcerte Paris», Le Devoir, 10 octobre 1973, 14.

59. Christiane Berthiaume, «Diane Dufresne les a eus, les Français», La Presse, 8 novembre 1973, B1. 
pratiquement chaque artiste d'ici se trouve un seul et même homme: Bruno Coquatrix, propriétaire de l'Olympia. Les quatre artistes précédemment mentionnés se sont produits sur cette scène (même si Félix Leclerc a fait ses débuts de 1950 sur des scènes plus modestes, il connait lui aussi la gloire sur les planches de l'Olympia). Il est très rare que d'autres salles soient fréquentées par les artistes québécois durant les deux décennies étudiées: parfois, un journaliste signale un passage à Bobino, une autre salle parisienne réputée, mais la vaste majorité des triomphes français ont lieu au même endroit. L'attachement de Bruno Coquatrix au Québec est bien connu et les journalistes ne manquent pas de souligner le grand nombre d'artistes québécois qu'il a engagés ${ }^{60}$. L’Olympia a la réputation d'être une salle prestigieuse et le simple fait d'y chanter semble garantir le triomphe, même si le spectacle en question est en fait le premier passage de l'artiste en France et qu'il est bien possible que son succès résulte d'une "mise en marché» habilement effectuée par Coquatrix.

De plus, la comparaison de certains articles publiés dans différents journaux au sujet d'un même spectacle permet de montrer qu'il y a occasionnellement exagération. Par exemple, le spectacle de Gilles Vigneault et de Pauline Julien, décrit avec enthousiasme par Échos-Vedettes comme un rempart contre l'envahissement de la France par la culture américaine ${ }^{61}$ et comme une consécration ${ }^{62}$ par La Presse, est considéré par Le Devoir comme un demi-succès ${ }^{63}$. Le correspondant parisien de ce quotidien affirme que Pauline Julien et Gilles Vigneault n'ont attiré que 200 personnes dans une salle pouvant en contenir plus de 1000. Il ajoute que les deux artistes font partie d'un spectacle intitulé Visages neufs de la chanson, présenté lorsqu'un autre spectacle fait relâche durant la semaine. De plus, il remarque que ceux qui applaudissent le plus pendant le spectacle sont des Canadiens. Le rempart contre l'américanisme décrit dans ÉchosVedettes et le succès critique rapporté dans La Presse semblent bien minces! Finalement, il est possible que d'autres spectacles aussi qualifiés de triomphes aient eu un succès moindre que ce qui a été rapporté par les journalistes d'ici.

Qu'est-ce qui pourrait justifier de tels emportements d'enthousiasme de la part des journalistes lorsqu'il est question des expériences françaises

60. E. R. [Edward Rémy], «Bruno Coquatrix meurt d'une crise cardiaque», Échos-Vedettes, 8 avril 1979, 6.

61. Sylviane Cahay, «Devant le public le plus connaisseur de Paris...», loc. cit.

62. Pierre Saint-Germain, «Malgré leur succès parisien.... loc. cit., 3.

63. Jean-Guy Pilon, «Demi-succès...», loc. cit., p. 8. 
des chanteurs et chanteuses québécois? Le prestige de la scène de l'Olympia a déjà été souligné, mais nous pouvons étendre cette aura à toute la France : le simple fait de s'y rendre, d'y être engagé pour quelques spectacles et d'être apprécié par quelques critiques est déjà considéré comme un exploit. Passer à l'Olympia est donc une étape importante dans la consécration des "grands » de la chanson. On peut également voir dans ce discours un désir de guérir les Québécois de leur supposé «complexe d'infériorité ${ }^{64}$ », un sentiment auquel les chroniqueurs artistiques font eux-mêmes référence à l'occasion ${ }^{65}$. En répétant que des artistes d'ici sont appréciés en France et capables de tenir l'affiche d'une prestigieuse salle parisienne sans renier leur appartenance au Québec, les journalistes de la presse artistique veulent probablement démontrer que la culture québécoise a autant de valeur que d'autres et que les Québécois ont toutes les raisons du monde d'être fiers leurs artistes.

\section{Aux États-Unis et ailleurs dans le monde}

Les ambitions internationales des artistes québécois ne se limitent pas à la France. Les tentatives de carrières américaines ou internationales se font cependant plus rares. Les journaux des années 1960 évoquent parfois le passage de vedettes québécoises aux États-Unis, mais il s'agit la plupart du temps d'épisodes très brefs qui ne sont pas associés au début d'une véritable carrière à l'étranger. Par exemple, Échos-Vedettes rapporte que les Baronets obtiennent en 1963 un engagement de deux semaines dans un club de Dallas ${ }^{66}$, ou encore La Presse nous parle d'une prestation offerte par Monique Leyrac à New York dans le cadre de la Semaine du Canada, organisée en l'honneur du centième anniversaire de la Confédération et de l'Expo ${ }^{67}$. Il faut attendre la fin de la décennie pour que la presse artis-

64. Voir à ce sujet Jocelyn Létourneau, «La Révolution tranquille, catégorie identitaire du Québec contemporain", dans Alain G. Gagnon et Michel Sarra-Bournet, dir., Duplessis, entre la Grande Noirceur et la société libérale (Montréal, Québec/Amérique, 1997), 95-118. L’auteur explique le rôle de la Grande Noirceur dans la construction du nouveau mythe des origines qu'est devenue la Révolution tranquille. Il affirme que la collectivité a construit sa représentation contemporaine en décrivant son passé comme une époque sombre, remplie de défaites démoralisantes, de traditionalisme et de "fatigue culturelle», comme l'exprimait Hubert Aquin (p. 116-117).

65. Jacques Duval, «Le club du disque », Échos-Vedettes, 10 décembre 1966, 11; Benoît L’Herbier, "17 vedettes ont participé à un spectacle insipide et médiocre», Échos-Vedettes, 17 juin 1972, 21 ; Anonyme, "Vigneault à Paris...», loc. cit.; et Raymond Laplante, "Un père tranquille... », loc. cit.

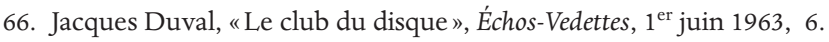

67. Simone Auger, «Avec Monique Leyrac, une merveilleuse soirée», La Presse, 6 mai 1967, 42. 
tique fasse état d'espoirs sérieux concernant d'éventuels succès aux ÉtatsUnis et au niveau international pour des vedettes québécoises. Deux cas attirent particulièrement l'attention des médias écrits: Ginette Reno et René Simard.

À la fin des années 1960, certains journalistes artistiques parlent des ambitions et du potentiel de Ginette Reno pour une carrière aux ÉtatsUnis. Claude Gingras vante ses mérites comme chanteuse de jazz et dit avoir l'impression qu'elle aurait beaucoup de succès chez les Américains, "non pas comme "french singer" mais comme chanteuse populaire assimilée $e^{68} »$. Échos-Vedettes abonde dans le même sens ${ }^{69}$. Le style musical de Ginette Reno est qualifié de "commercial», mais les critiques semblent s'entendre pour affirmer qu'il s'agit quand même d'un commercial de qualité $^{70}$, voire de grande classe ${ }^{71}$. À partir de 1969, les journaux rapportent la participation de Ginette Reno à des émissions de télévision et à des spectacles aux États-Unis et même en Angleterre. Les tentatives de la chanteuse pour percer le marché anglophone nord-américain et international sont perçues très positivement: Échos-Vedettes croit que Ginette Reno est l'artiste "qui nous représenterait le plus dignement à l'étranger ${ }^{72}$ " et $\mathrm{La}$ Presse décrit sa carrière anglaise comme un défi passionnant ${ }^{73}$. La barrière linguistique ne représente pas un problème aux yeux des journalistes: René Homier-Roy affirme même que "c'est en anglais, surtout, que la voix de Ginette Reno atteint toute sa plénitude, toute sa rondeur ${ }^{74}$ ». Cependant, il semble que la route vers le succès américain soit beaucoup plus longue et difficile que pour les triomphes français: Ginette Reno choisit de s'exiler pendant un an en Californie au milieu des années 1970 et si certains articles rapportent parfois des succès et des critiques positives de la presse américaine ${ }^{75}$, la véritable consécration semble se faire attendre encore et toujours.

68. Claude Gingras, «Ginette Reno: de la voix, du cœur et du rythme!», La Presse, 16 janvier $1968,22$.

69. Michel Lecompte, "Une nouvelle vedette des grandes scènes: Ginette Reno", ÉchosVedettes, 27 janvier 1968, 5.

70. Claude Gingras, «De Renée Claude à Ginette Reno », La Presse, 20 avril 1968, 33.

71. Jacques Duval, «Le club du disque», Échos-Vedettes, 20 avril 1968, 15.

72. Michel Lecompte, «Une nouvelle vedette... », loc. cit., 5.

73. R. H.-R. [René Homier-Roy], «Enfin, la carrière anglaise de Ginette Reno démarre: elle chante au Savoy», La Presse, magazine Spec, 29 janvier 1970, 3.

74. René Homier-Roy, «Les bons et les mauvais. L’avant-dernière Ginette Reno », La Presse, magazine Spec, 4 septembre 1969, 14.

75. André Robert, "Les journalistes américains font déjà l'éloge de Ginette Reno», ÉchosVedettes, 10 avril 1976, 6. 
L'évolution de la carrière de René Simard se déroule différemment. Découvert en 1971 par Guy Cloutier ${ }^{76}$, il remporte auprès du public québécois un succès immédiat et fulgurant: «En cinq mois, il a vendu plus de microsillons que la plupart des autres chanteurs dans toute leur carrière $^{77}$.» Lors de sa participation à un festival de la chanson au Japon au cours duquel il remporte le premier prix, tous les espoirs semblent permis, du moins selon la rédaction d'Échos-Vedettes qui titre: "Après Sinatra, Presley et les Beatles: René Simard ${ }^{78}$ ?» Pendant ce temps, La Presse analyse le phénomène en tant qu'entreprise commerciale générant des sommes considérées comme astronomiques pour le show-business québécois ${ }^{79}$. Tous ces espoirs semblent réellement pris au sérieux: même l'auguste Devoir informe ses lecteurs des développements de la carrière du jeune prodige local ${ }^{80}$. Malgré le fait que René Simard anime sa propre émission de télévision au Canada anglais et qu'il se soit produit sur les scènes de Las Vegas ${ }^{81}$, force est de constater qu'à mesure que l'enfant devient un adolescent puis un jeune homme, l'enthousiasme baisse dans la presse artistique et les rêves de le voir faire une grande carrière internationale s'estompent vers la fin des années 1970.

En somme, les expériences américaines et françaises des artistes sont vécues et rapportées de manière bien différente par la presse artistique. La présence de chanteurs et chanteuses d'ici est à la fois plus précoce, plus nombreuse et plus soutenue en France qu'aux États-Unis et ailleurs dans le monde. De plus, il semble exister un certain clivage entre ceux qui se produisent sur les scènes françaises et ceux qui tentent leur chance auprès du marché anglo-saxon. Les seconds font surtout partie de la catégorie des "vedettes populaires»: Ginette Reno et René Simard sont des interprètes dont les principaux atouts sont leur voix exceptionnelle et leur sens du spectacle. Si la qualité des interprétations de Ginette Reno fait pratiquement l'unanimité, il reste qu'elle est étiquetée chanteuse commerciale. Le "phénomène Céline Dion» est encore loin, mais il commence à

76. Pierre Trudel, «René Simard, 10 ans, l'étonnante trouvaille de Guy Cloutier», ÉchosVedettes, 11 septembre 1971, 5.

77. Pierre Vincent, «Petit René Simard deviendra-t-il grand?», La Presse, 9 mars 1972, C4.

78. Pierre Trudel, «Après Sinatra, Presley et les Beatles: René Simard?», Échos-Vedettes, 29 juin $1974,6$.

79. Christiane Berthiaume, «Le p’tit Simard: une "entreprise” compliquée», La Presse, 11 juillet 1974, B1.

80. Yves Taschereau, «René Simard tournera un film à Hollywood avec Liz Taylor », Le Devoir, 19 août 1974, 10.

81. Bruno Dostie, «Les journées studieuses de René Simard», La Presse, 5 août 1978, D1. 
poindre à l'horizon: les cas mentionnés ont exploré les possibilités du marché américain et ils préfigurent ce qui deviendra, dans les années 1990, le modèle de l'artiste québécois fonceur, travaillant et performant au niveau commercial ${ }^{82}$. De leur côté, Félix Leclerc, Gilles Vigneault, Robert Charlebois et Diane Dufresne sont généralement décrits comme des artistes authentiques. Les deux premiers entrent dans la catégorie des poètes et des chansonniers et si Charlebois et Dufresne interprètent surtout des textes écrits par d'autres personnes, ils personnalisent leurs chansons et font preuve d'une telle créativité musicale et scénique qu'ils obtiennent aussi le statut de "vrais artistes». Tout en réalisant une "conquête» de la France, ils participent au processus d'émancipation culturelle du Québec vis-à-vis de cette dernière en adoptant des caractéristiques linguistiques et scénographiques qualifiées de choquantes et de déstabilisantes pour le public de l'Hexagone. Pendant les années 1960 et 1970, la presse artistique accorde à la France le pouvoir de consacrer les "grands» de la chanson, alors que pour les États-Unis, elle rêve de succès commerciaux qui ne se matérialisent pas encore, mais dont les possibilités sont envisagées.

\section{L'INTÉGRATION À L'AMÉRIQUE DU NORD: LES RÉACTIONS FACE À L'INFLUENCE MUSICALE ANGLO-SAXONNE}

Si l'exportation des artistes vers le monde anglo-saxon fait encore surtout partie des rêves et des espoirs, le Québec entretient tout de même des relations étroites avec la musique américaine. D’abord, l'importance du phénomène musical et la place centrale de la musique rock dans la culture des jeunes sont sensiblement les mêmes au Québec que dans le reste de l'Occident $^{83}$. Les Beatles connaissent autant de succès ici qu'ailleurs et les grandes modes musicales des années 1960 et 1970 sont suivies par les Québécois et les Québécoises aussi fidèlement que par les autres jeunes Occidentaux.

Les chanteurs et les musiciens d'ici créent des chansons en empruntant aux styles musicaux populaires de leur époque parce qu'ils les apprécient eux-mêmes et aussi pour correspondre aux goûts du public. La musique populaire composée au Québec est donc marquée par l’imitation et l'adoption de plusieurs courants musicaux différents qui peuvent se succéder, se croiser ou se mélanger. La très grande majorité de cette musique

82. Frédéric Demers, Céline Dion..., op. cit., 129.

83. Doug Owram, Born at the Right Time, a History of the Baby-Boom Generation (Toronto, University of Toronto Press, 1996), 190. 
demeure tout de même accompagnée de paroles en français. Tous les styles musicaux en provenance du monde anglo-saxon sont-ils estimés de la même manière dans la presse artistique? Certains styles ou certaines modes sont-ils perçus et décrits comme étant plus authentiquement québécois que d'autres?

\section{Le yé-yé}

Voyons d'abord le cas d'un phénomène important du début des années 1960 : le yé-yé, que les journalistes de l'époque classent généralement dans le domaine de la "chansonnette populaire». Caractérisé par la traduction en français de hits américains à la musique simple et rythmée ainsi que par un nombre impressionnant de groupes et d'idoles, ce style musical est perçu par certains rédacteurs comme une des formes les plus discutables de la musique populaire ${ }^{84}$. Ces journalistes n'hésitent pas à le qualifier de tintamarre ${ }^{85}$ et certains affirment que le yé-yé menace jusqu'à l'existence de la "vraie» chanson française. Parlant du yé-yé en France, Lise Payette écrit: «Pendant longtemps on a cru que la chanson française était complètement enterrée», car le public "a été perdu par ces jeunes dont le spectacle n'était plus fait que de bruit, de cris, de sièges brisés, et d'une gymnastique digne des meilleurs contorsionnistes de cirque ${ }^{86}$.» Bref, le yé-yé est souvent victime d'un jugement négatif et est associé à une musique de piètre qualité.

Cependant, plusieurs chroniqueurs accordent certains mérites au yé-yé et à ses idoles. Par exemple, Pierre Bourgault dit des jeunes vedettes de la chanson que le fait qu'elles chantent toutes en français redonne aux Canadiens français le goût d'entendre de la musique dans leur langue ${ }^{87}$. La Presse affirme également que «la musique des jeunes, chez nous, a ses particularités propres ${ }^{88}$ » et perçoit comme un signe de vitalité le fait que les jeunes aient adapté et digéré la musique américaine pour s'en emparer et en faire quelque chose de différent ${ }^{89}$.

84. Jean Vallerand, «De la récupération des anti-musicaux et de la revalorisation du "yé-yé” ", La Presse, cahier Arts et lettres, 27 mars 1965, 9.

85. Francine Laurendeau, «De l'autre côté de l’océan, les nouvelles sont bonnes... La France a rapatrié le yé-yé», La Presse, section Magazine, 22 mai 1965, 18.

86. Lise Payette, "La chanson gagne ses lettres de noblesse», La Presse, cahier Arts et lettres, 2 mai $1964,10$.

87. Pierre Bourgault, «Les jeunes vedettes de la chanson... À la conquête du Québec», $L a$ Presse, section Magazine, 9 novembre 1963, 4.

88. Jean-Pierre Bonhomme, «Vitalité», La Presse, section Magazine, 22 mai 1965, 2.

89. Id. 
Le yé-yé ne fait pas l'unanimité: parfois décrié comme de la musique pauvre qui n'est faite que de rythmes, de bruits et de cris, il est regardé comme un curieux phénomène. Cependant, il est aussi considéré comme un style qui fait partie de l'époque et de la culture de la jeunesse des années 1960. L'intérêt porté aux idoles et aux groupes québécois ${ }^{90}$ montre à tout le moins que le phénomène attire l'attention de la presse artistique et que la perception positive semble l'emporter: la mode américaine a été récupérée avec un certain succès, les chansons en français demeurent populaires et cela semble rassurer plusieurs journalistes de la presse artistique à propos de la vigueur de la culture québécoise.

\section{Le rock}

À la fin des années 1960, le rock semble accepté unanimement comme une partie intégrante de la musique québécoise. Ce style musical trouve une de ses plus grandes vedettes en la personne de Robert Charlebois, un artiste à la fois très populaire auprès du public et fort apprécié par les chroniqueurs de la presse artistique. Il est connu en tant que chansonnier depuis 1965, mais c'est durant un voyage en Californie qu'il adopte un style musical complètement nouveau, inspiré des groupes américains et du monde hippie. Claude Gingras résume les mérites de Charlebois ainsi : «Il nous propose une musique qui retient plusieurs des meilleures trouvailles mélodiques, sonores et littéraires des groupes américains et européens les plus avancés et il applique ces trouvailles au problème du Québec pris dans l'environnement américain ${ }^{91}$.»

C'est dans les paroles que les journalistes trouvent cette application au "problème du Québec». Ils affirment que Charlebois exprime "les réalités omniprésentes du mode de vie canadien-français ${ }^{92}$ » dans leurs dimensions modernes: "Les chansons de Robert Charlebois sont urbaines et ouvertes au monde extérieur. Elles révèlent une mentalité d'emblée urbaine ${ }^{93}$.» De plus, «Charlebois semble en effet montrer que l’on peut être Québécois et cependant pas enfermé dans un nationalisme blindé, que l'on peut être à l'aise partout dans le monde ${ }^{94}$.» Même son usage du joual est perçu

90. Pierre Bourgault, «Les jeunes vedettes de la chanson... », loc. cit., 4-9; Lise Lapierre, «Une enquête sur le phénomène des groupes yé-yé!», Échos-Vedettes, 13 novembre 1965, 5-9; et Pierre Trudel, «Les groupes», Échos-Vedettes, 17 septembre 1966, 16-17.

91. Claude Gingras, «Disques: Charlebois, Lautrec, Arnaud, les Sinners», La Presse, 16 mars 1968, 29.

92. Anonyme, «Les pages de Loulou: de Californie, Robert Charlebois nous rapporte le "baroque and roll" ", Échos-Vedettes, 24 février 1968, 13.

93. Placide Gaboury, «Robert Charlebois : chantre des villes?», Le Devoir, 29 mars 1969, 22. 94. Id. 
positivement, comme quelque chose qui reflète la réalité québécoise et ajoute à la lucidité des textes ${ }^{95}$. Cela est si vrai que lorsque Charlebois refuse de s'enfermer dans le joual et adopte un style moins révolutionnaire, quelques chroniqueurs se demandent si cette volte-face ne constitue pas une trahison ${ }^{96}$ !

Robert Charlebois n'est pas le seul Québécois à s'inspirer de la musique de la contre-culture et du rock américain: les Sinners (qui deviennent en 1968 la Révolution française) empruntent la même voie. Dans les années 1970, Richard et Marie-Claire Séguin, de même que le groupe Harmonium, jouent aussi une musique résolument inspirée du folk-rock et du mouvement hippie. Des influences musicales semblables se retrouvent dans les chansons de Beau Dommage. Pour sa part, la formation Offenbach est présentée comme le premier véritable groupe rock québécois ${ }^{97}$. Tous ces artistes ne reçoivent pas toujours des critiques aussi enthousiastes que Robert Charlebois, mais le courant musical dans lequel ils s'inscrivent est perçu très positivement. Peu après leur introduction dans la musique locale, le rock et ses diverses déclinaisons ne sont plus seulement considérés comme un courant musical qui influence les musiciens québécois: on parle d’un véritable rock québécois.

\section{Le western}

Tous les styles musicaux adoptés par les musiciens québécois ne sont pas acceptés d'emblée comme faisant partie de la culture locale. À ce chapitre, le style western serait à classer parmi les mal aimés. Même si ce genre musical a des adeptes au Québec depuis la Deuxième Guerre mondiale ${ }^{98}$, le phénomène de la chanson western ne semble pas intéresser la presse artistique avant la fin des années 1960. À cette époque, les journalistes remarquent un "renouveau de la chanson western ${ }^{99}$ " qui se traduit notamment par la création du Festival western de Saint-Tite, en Mauricie. L'existence de ce festival suscite des questions chez les rédacteurs de la presse artistique et certains observent cette fête populaire comme le

95. Raymond Laplante, «Un père tranquille...», loc. cit., 7.

96. Pierre Brousseau, «Charlebois nous a-t-il trahis?», Échos-Vedettes, 30 avril 1978, 18; et Pierre Beaulieu, “"C'est devenu à la mode d'être anti-Charlebois”", La Presse, 23 juin 1978, C1.

97. Georges-Hébert Germain, "Champion poids lourd du rock gaulois: Offenbach », La Presse, 6 novembre 1975 , B1.

98. Robert Giroux, Constance Harvard et Rock Lapalme, Le guide de la chanson québécoise (Montréal, Éditions Triptyque, 1996), 23.

99. Edward Rémy, «25 ans pour Willie Lamothe», Échos-Vedettes, 9 août 1969, 4. 
feraient des anthropologues ${ }^{100}$. Ce qu'il y a de particulier dans le cas du western, c'est que ce n'est pas seulement la musique elle-même qui est jugée négativement par certains journalistes, mais bien toute la culture qui l'entoure. L'imagerie du far-west et des cow-boys qui accompagne la musique western est perçue comme étrangère à la culture québécoise. Son imitation et son adoption par une partie de la population sont décrites comme un symptôme d'aliénation culturelle, causée par le colonialisme américain $^{101}$. Joseph Rudel-Tessier s'exprime ainsi au sujet du Festival western: «Si je n’avais pas été préparé par la télévision, je n’en aurais pas cru mes oreilles quand j'entendais ces Québécois m’expliquer que ce festival western, que cette musique, que ces costumes, que ce rodéo, ce décor, ressuscitaient "nos" traditions ${ }^{102}$ !"

Plus loin dans le même numéro, Yves Leclerc écrit: «Le plus extraordinaire de tout cela, c'est que ce Festival, basé sur la mythologie d'un farwest imaginaire qui n'a rien à voir avec le décor de la Mauricie, finit par "sonner" vrai. Parce que les gens y croient, qu'ils s'y reconnaissent ${ }^{103}$." L'année suivante, La Presse publie une lettre destinée au chanteur Willie Lamothe dans laquelle on écrit que «dans notre pays québécois, beaucoup de gens s'imaginent que nos ancêtres à tous étaient des cow-boys ${ }^{104}$ ", croyance qualifiée "d'idée saugrenue» et pour laquelle l'auteur de la lettre en question blâme directement le chanteur: "vous aurez exercé une bien mauvaise influence sur vos compatriotes du pays de Québec!»

Si la section artistique de La Presse se montre plutôt acerbe envers le western et ses vedettes, Échos-Vedettes porte sur le phénomène un jugement différent. Sans pour autant faire l'apologie du western, ses artistes et son public y semblent plus appréciés: les 25 ans de carrière de Willie Lamothe sont soulignés ${ }^{105}$, ainsi que quelques ventes de disques impressionnantes réalisées par les artistes western ${ }^{106}$. Lorsqu'en 1979 Willie Lamothe reçoit l'Ordre du Canada, l'événement est considéré comme un

100. [Joseph] Rudel-Tessier, “On est pas français, on est western!», La Presse, magazine Spec, 18 septembre 1969, 9; et Yves Leclerc, "Chassez le western, il revient au galop », La Presse, magazine Spec, 18 septembre 1969, 10-15.

101. Ibid., p. 9.

102. Id.

103. Yves Leclerc, "Chassez le western... », loc. cit., 15.

104. P. P. H., «Lettre aux idoles », La Presse, magazine Spec, 17 septembre 1970, H7.

105. Edward Rémy, « 25 ans...», loc. cit., 4.

106. Michèle Tremblay, «La dernière rage des Québécois : le western », Échos-Vedettes, 18 août 1973, 28-29. 
honneur bien mérité ${ }^{107}$. Même si le caractère «québécois» de la musique western n'est pas discuté dans les pages d'Échos-Vedettes, on s'y intéresse davantage que dans La Presse, ce qui laisse supposer qu'il est davantage accepté par les rédacteurs comme une partie de la culture québécoise.

\section{Les styles en parallèle}

La différence d'appréciation et d'acceptation entre le rock et le western est assez claire : à partir de la fin des années 1960, le rock est accepté à peu près unanimement par la presse artistique, alors que le western fait parfois l'objet d'un jugement négatif, voire méprisant. Pourtant, ces deux styles musicaux sont de proches parents et proviennent des États-Unis. Si l'exportation massive de la culture américaine cause effectivement l'aliénation des Québécois et des Québécoises, l'adoption du rock par les musiciens d'ici ne devrait-elle pas être également considérée comme un symptôme, au même titre que la popularité du western et des films de cow-boys? Comment expliquer cette différence de perception?

L'explication principale est générationnelle: le rock est la musique des baby-boomers. En plus d'être le style musical le plus populaire auprès des jeunes Occidentaux, le rock est un véhicule qui exprime la contestation sociale et politique ainsi que les préoccupations de la jeunesse des années 1960 et $1970^{108}$. Les artistes d'ici écrivent des chansons qui réfèrent à la réalité locale en abordant, entre autres, la question de la libération nationale ou celle des Amérindiens, mais dans l'essence, ce qu'ils font n'est pas différent de ce que font les musiciens des États-Unis ou de la GrandeBretagne. Il s'agit d'un courant mondial. Qu'il soit d'ici ou d'ailleurs, le rock véhicule les valeurs de la jeunesse : anticonformisme, liberté, contestation du système. C'est la musique favorite des jeunes modernes, conscientisés et politisés.

Souvent, la presse artistique souligne combien les chansons et les artistes qui les interprètent reflètent les valeurs du public qui les apprécie. On peut penser par exemple à Richard et Marie-Claire Séguin, lorsqu'ils abordent le thème des Amérindiens. On dit à ce sujet que leurs chansons contiennent «des prises de positions [sic] pas du tout négligeables et, à en juger par l'accueil qu'on fait en spectacle à ces deux chansons, assez lar-

107. Marc Chatelle, «Willie Lamothe est décoré par le gouverneur-général du Canada », ÉchosVedettes, 4 novembre 1979, 4.

108. Doug Owram, Born at the Right Time..., op. cit., 185- à 196. Voir également Paul-André Linteau et al., Histoire du Québec contemporain, op. cit., 764. 
gement partagées par le public ${ }^{109}$ ». Les membres du duo sont aussi décrits comme des artistes qui refusent de s'intégrer au système ${ }^{110}$ et qui «représentent ici les tendances écologiques de toute une jeunesse ${ }^{111}$ ». Moins engagé politiquement, Beau Dommage a le mérite d'employer "un langage étroitement lié aux réalités qui brassent ce monde-là et qui le bordent le soir dans son lit. Ils parlent montréalais pure laine et pure sloche ${ }^{112}$.» En résumé, les artistes d'ici qui font de la musique rock permettent aux jeunes Québécois et Québécoises de faire partie du même courant que les autres jeunes Occidentaux, tout en abordant des réalités locales et en reflétant les valeurs et les préoccupations qui leur importent le plus.

Il n'en va pas du tout de même pour le western. D'abord, le monde entourant ce style musical est défini comme différent du reste de la scène musicale: "C'est, d'une certaine façon, un phénomène "underground" que le profane ne découvre pas aisément ${ }^{113}$.» Le public provient du «bon peuple ${ }^{114} »$. Il est fidèle, stable et associé au monde rural ${ }^{115}$. Il est également nombreux, car le grand nombre de disques vendus par les chanteurs western est parfois souligné. Les vedettes western sont aussi décrites comme simples et affables ${ }^{116}$. La musique western, dans son essence et dans ses paroles, est fortement associée à la ruralité traditionnelle: un rédacteur la décrit comme «l'expression de la joie de vivre des pionniers qui ont fait du continent nord-américain ce qu'il est ${ }^{117}$ ", alors qu'un autre affirme: «Il y a dans la musique western, une certaine naïveté désarmante, une sorte de tendresse à l'eau de rose qui font que les Québécois, les ruraux surtout, quoiqu'il ne faut jurer de rien, se reconnaissent dans cette musique qui, au fond est comme eux, simple et sans prétention ${ }^{118}$.» Cette simplicité au niveau des paroles est loin d'être toujours perçue positivement: René Homier-Roy décrit les textes des chansons western comme

109. René Homier-Roy, "Gilles Valiquette et les Séguin », La Presse, 10 mars 1973, C4.

110. René Homier-Roy, «Les petits Séguin, entre la mer et l'eau douce», La Presse, $1^{\mathrm{er}}$ mars 1973, C1.

111. Georges-Hébert Germain, «Des Séguin à Valiquette. La musique passe de la campagne à la ville», La Presse, 27 février 1975, D1.

112. Georges-Hébert Germain, "Un clin d'œil à Beau Dommage », La Presse, 28 novembre 1974, C1.

113. Yves Leclerc et Pierre Vincent, «Elvis avait chassé les westerns, Willie les ramène au grand galop», La Presse, 22 avril 1971, E1.

114. Yves Leclerc, "Chassez le western... », loc. cit., 10.

115. Michèle Tremblay, "La dernière rage.... », loc. cit., 28-29.

116. Ibid.

117. Edward Rémy, « 25 ans... », loc. cit., 4.

118. Michèle Tremblay, «La dernière rage... ", loc. cit., 29. 
d'«invraisemblables banalités ${ }^{119}$ ». Aux yeux de la jeunesse, le western représente certainement quelque chose de complètement différent du rock. L'association de cette musique avec la ruralité et avec des textes simples, banals, au contenu essentiellement sentimental, fait en sorte qu'elle ne correspond pas aux aspirations de la majorité des membres de la génération des baby-boomers. Rappelons enfin que les journalistes cités écrivent dans des journaux montréalais: cela explique peut-être aussi pourquoi ils manifestent plus d'ouverture face au rock, associé à l'urbanité, qu'au western, associé à une ruralité traditionnelle et à une «Grande Noirceur» dont ils cherchent à s'éloigner.

La différence de perception et d'acceptation des styles musicaux ne semble donc pas relever de leur provenance culturelle, mais davantage des goûts de la jeunesse et des valeurs associées à chacun des genres en question. La comparaison de l'accueil réservé à trois styles importés du monde anglo-saxon le démontre bien. La grande vogue du yé-yé au début des années 1960 auprès des jeunes et la popularité des versions françaises font en sorte que même si ce style est critiqué, il est perçu positivement par plusieurs journalistes parce que les productions locales sont faites en français. L'importance du rock pour la grande majorité de la jeunesse occidentale et les thématiques abordées par les artistes locaux en font le style le plus important durant les deux décennies étudiées ici. Il est "parfaitement accordé à l'esprit de la jeunesse montante en ce qu'il retentit avant tout comme un immense cri de libération et de joie ${ }^{120} »$. L'adoption de cette musique par les artistes et le public québécois n'est jamais questionnée durant les années 1960 et 1970. Estimé moins populaire auprès des jeunes et associé à un monde traditionnel et rural alors contesté, le western est perçu par plusieurs journalistes comme un symptôme d'aliénation culturelle.

\section{CONCLUSION}

L'analyse du discours journalistique sur la chanson permet de constater qu'au niveau identitaire, le rapport à l'Autre évolue durant la période étudiée. Du côté français, un fort désir de conquérir le public se manifeste. Cependant, cette ambition est mêlée à la volonté croissante de se distinguer de la France. La relation culturelle entre la France et le Québec

119. René Homier-Roy, «On en dira du bien quand “il” sera mort!», La Presse, 22 avril 1971, E3.

120. François Ricard, La génération lyrique, essai sur la vie et l'œuvre des premiers-nés du baby-boom (Montréal, Boréal, 1994), 122. 
demeure importante: la "mère patrie» reste un lieu de consécration aux yeux des journalistes artistiques. En même temps, ceux-ci semblent désirer l'émancipation culturelle du Québec. Les succès des artistes québécois en France sont applaudis, mais les chroniqueurs manifestent encore plus de fierté lorsqu'ils constatent leur spécificité. Ce désir d'émancipation crôit au cours de la période. Au début des années 1960, «Le Canadien» Félix Leclerc est vu comme un représentant à part entière de la chanson française, alors qu'à la fin des années 1960 et durant les années 1970, la satisfaction de voir que les artistes demeurent fidèles à leur identité québécoise et montrent aux Français qu'ils sont différents s'exprime davantage.

Les relations avec les États-Unis et le monde anglo-saxon sont plus complexes. Les tentatives d'exportation sont perçues positivement, mais les attentes à cet égard paraissent bien différentes que dans le cas de la France: les artistes qui essaient de percer le marché américain sont moins nombreux et qualifiés de chanteurs commerciaux. Conquérir l'Amérique anglophone n'est pas nécessaire pour gagner le respect et l'admiration de la presse artistique, mais les tentatives faites en ce sens sont bien perçues. C'est cependant au niveau des influences musicales extérieures que le rapport à l'Autre s'exprime le mieux. En général, les styles musicaux en provenance des États-Unis sont accueillis de manière positive par les journalistes artistiques. La chanson québécoise s'accommode particulièrement bien des différents courants du rock and roll. Cependant, certains styles, dont le western, sont moins facilement adoptés comme étant authentiquement québécois. En quelque sorte, les journalistes artistiques de l'époque effectuent une prise de conscience du caractère nord-américain de la chanson québécoise. La plupart du temps, cela n'est pas considéré comme une menace, mais quelques traits de cette nord-américanité sont contestés et parfois rejetés par certains chroniqueurs, surtout lorsqu'ils ne correspondent pas aux goûts, aux valeurs et aux aspirations de la jeunesse urbaine.

Que l'on parle de l'exportation des artistes québécois à l'étranger ou de l'intégration des influences musicales extérieures, les perceptions des chroniqueurs et journalistes semblent souvent dépendre de la langue. Les perceptions positives du yé-yé et du rock découlent largement du fait que les artistes locaux chantent en français, tandis que la distinction par rapport à la France passe fréquemment par l'usage du français oral populaire, ou par cet accent québécois qu'il ne faut pas perdre en Europe. Si nous constatons que l'identité collective des Québécois s'est cristallisée autour du français durant la Révolution tranquille, nous remarquons aussi avec 
surprise que lorsque René Simard ou Ginette Reno chantent en anglais, ils ne subissent aucun reproche de la part des chroniqueurs. On peut toutefois se demander comment a évolué cet aspect au cours des décennies suivantes. Nous songeons surtout à la signification des critiques adressées aux Québécois francophones qui chantent dans la langue de Shakespeare, exprimées de manière acerbe par le groupe humoristique Rock et Belles Oreilles dans la chanson «I Want to Pogne» à la fin des années 1980. Les Québécois francophones sont-ils nombreux à juger que ceux des leurs qui chantent en anglais sont les "Judas of the French Canada $^{121}$ "? Ces critiques expriment-elles une inquiétude plus grande face à l'influence culturelle et à l'attraction commerciale du géant américain?

Les relations culturelles et identitaires entre le Québec et le reste du Canada n'ont pas été abordées dans le cadre de cet article, car les sources employées contenaient très peu de références à ce sujet. La question mérite quand même d'être soulevée: pourquoi les journalistes parlent-ils si peu du Canada anglais et que signifie la quasi-absence de cet "Autre» dans leur discours sur la chanson? Est-ce une stratégie subconsciente visant à démontrer que les Canadiens anglais n’ont pas de culture spécifique ou qu'ils sont assimilés aux Américains? Il faudrait effectuer d'autres recherches pour analyser le jugement porté par les Québécois sur la culture canadienne-anglaise.

L'analyse du discours de la presse artistique montre bien son rôle dans le processus de construction sociale de la chanson québécoise : en relatant les expériences des artistes locaux à l'étranger et en jugeant de la valeur respective de différents styles musicaux, journalistes et chroniqueurs contribuent à définir ce qu'est un "véritable» artiste de la chanson québécoise. Ce discours valorise également des traits attribués à toute la collectivité, pour donner l'image d'une culture nationale tournée vers la France, capable d'y être reconnue et appréciée tout en étant de plus en plus affranchie de celle-ci. L'attraction et l'influence américaine sont bien présentes et perçues plutôt positivement, même si une ambivalence à ce sujet demeure.

Le discours véhiculé par la presse artistique au sujet de la chanson fait partie de tout un processus de valorisation de la culture québécoise. Les journalistes accompagnent les politiciens et les intellectuels de leur

121. Pour le texte et le fichier audio de cette chanson, voir le site Internet http://www. rocketbellesoreilles.com. 
époque désireux de démontrer que le Québec des années 1960 et 1970 est plus moderne, plus éclairé, plus riche matériellement et culturellement que celui de la "Grande Noirceur» et des époques précédentes. La presse artistique participe à la création du nouveau mythe fondateur qu'est devenue la Révolution tranquille en dressant le portrait d'une culture nationale spécifique permettant à la collectivité de trouver de nouveaux points de repère auxquels elle peut désormais s'identifier. C'est ainsi que des chansons deviennent des hymnes et que des chanteurs et des chanteuses font partie des nouveaux héros. 